\title{
PB15 Kodlu Pigmentler; Sentezi, Karakterizasyonu ve Endüstriyel Uygulamaları
}

\author{
Yusuf YILMAZ1 ${ }^{\mathscr{P}(D)}$, Sibel BAYIL2 2 (D) \\ ${ }^{1}$ Gaziantep Üniversitesi Naci Topçuoğlu Meslek Yüksekokulu, ${ }^{2}$ Gaziantep Üniversitesi Sağllk Hizmetleri Meslek Yüksek Okulu, Gaziantep \\ ${ }^{1}$ https://orcid.org/0000-0003-4363-0427, ${ }^{2}$ https://orcid.org/0000-0003-0254-6915 \\ 凹: ysfyilmaz60@gmail.com
}

\begin{abstract}
ÖZET
Ftalosiyaninler (Pc'ler) yapisal olarak makro halkalı porfirin türevli bileşiklere benzemektedirler. Ftalosiyaninlerin genellikle farkl çözünürlük, renk şiddeti ve kararlılık açısından birbirinden ayrı en az iki kristal modifikasyonu bulunmaktadır. Renk şiddeti (pigment özelliği) en kuvvetli olan türevleri bakır, kobalt ve nikel ftalosiyaninlerdir. Pigment olarak ticari öneme sahip tek ftalosiyanin bakır ftalosiyaninlerdir. Bakır ftalosiyaninler (CuPc, PB15), sayılan bu üstün özellikleri nedeniyle, baskı mürekkepleri, tekstil, kâğıt, kauçuk ve plastiklerin renklendirilmesinde ve hatta inşaat ve endüstriyel boya üretiminde kullanılmaktadır. $\mathrm{Bu}$ çalışmada, ülkemizde üretilmeyen ancak ithal edilip yaygın bir şekilde kullanılan ftalosiyanin türevli, PB15:1 kodlu (bu kapsamda sentezlenen pigmente HNS 15:1 kodu verilmiştir) pigmentin sentezi, karakterizasyonu ve endüstriyel uygulama örnekleri yapılmıştır. Pigmentin sentezinde uygun başlangıç maddeleri yă̆ isıtmalı bir reaktörde karıştırılmış ve ham ürün elde edilmiştir. Reaksiyondan elde edilen ham ürün yıkanmış, filtre edilmiş ve kurutulmuştur. Elde edien pigment UV-vis., FTIR, MS gibi spektroskopik teknikler ve elementel analiz ile karakterize edilmiştir. Pigmentin endüstriyel uygunluk denemeleri masterbatch, suni deri ve pigment pasta sektörlerinde yapılmıştır.
\end{abstract}

\section{PB15 Coded Pigments; Synthesis, Characterization and Industrial Applications}

\section{ABSTRACT}

Phthalocyanines (Pcs) are structurally similar to macrocyclicporphyrin-derived compounds. Phthalocyanines generally have at least two crystal modifications that are distinct from each other in terms of solubility, color intensity and stability. The strongest derivatives in terms of color intensity (pigment property) are copper, cobalt and nickel phthalocyanines. The only phthalocyanine having commercial value as pigment is copper phthalocyanine. Copper phthalocyanines are also used in printing inks, textiles, paper, rubber and plastics, and even in the production of construction and industrial paint thanks to their outstanding properties. In this study, production, characterization and experimentation on industrial applications of the phthalocyanine-derived, PB15: 1 coded pigment (In this study, HNS 15: 1 code is given to the synthesized pigment) which is not produced but widely used in our country, have been successfully implemented. In the synthesis of the pigment, suitable starting materials were mixed in an oil-heated reactor and the crude product was obtained. The crude product from the reaction was washed, filtered and dried. The obtained pigment was characterized by spectroscopic techniques such as UV-vis., FTIR, MS, and elemental analysis. Industrial compatibility tests of pigment are made in the masterbatch, artificial leather and pigment pastry sectors.

\section{Araştırma Makalesi}

Makale Tarihçesi

Geliş Tarihi : $\quad 15.12 .2018$

Kabul Tarihi : 31.01 .2019

Anahtar Kelimeler

Ftalosiyaninler

$\mathrm{CuPc}$

Pigmentler

PB15:1

Ftalikanhidrit

To Cite : Yılmaz Y, Bayıl S 2019. PB15 kodlu pigmentler; sentezi, karakterizasyonu ve endüstriyel uygulamaları. KSÜ Tarım ve Doğa Derg 22(3): 466-472. DOI: 10.18016/ksutarimdoga.vi.497752 


\section{GİRIŞ}

Ftalosiyanin $(\mathrm{Pc})$ ismi Yunanca "naphtha = mineral yağı" ve "cyanine $=$ koyu mavi" kelimelerinin bileşiminden oluşturulmuş̧ur. Ftalosiyanin terimi, sarımsı yeşilden kırmızımsı maviye kadar değişen renk tonlarına sahiporganik boyar madde sinıfinı tanımlamak için ilk defa 1933 yılında R. P. Linstead tarafından kullanılmıştır. Ftalosiyaninlerin ve metal komplekslerinin (MPc) yapıları, Linstead ve çalışma arkadaşları tarafından, 1930-1940 yılları arasında belirlenmiştir (Robertson, 1936, Yıldız ve ark., 2009). Ftalosiyaninler periyodik tablodaki çoğu metal ile kompleks oluşturmakla beraber $\mathrm{B}, \mathrm{Si}, \mathrm{Ge}$, ve As gibi yarı metaller ile de farklı koordinasyon sayılarına ve geometrik şekillere sahip kompleks meydana getirebilmektedir. Örneğin $\mathrm{Cu}, \mathrm{Ni}$ veya Pt'in kare düzlem ftalosiyaninkomplekslerinin koordinasyon sayısı 4'tür. Diğer taraftan daha fazla koordinasyon sayısına sahip metaller ve ilave ligandlar (su, amonyak gibi) ile kare piramit, düzgün dört yüzlü veya sekiz yüzlü ftalosiyaninkompleklesleri de mevcuttur (Durmuş ve Nyokong, 2007).

Ftalosiyaninler yapisal olarak makro halkalı porfirin türevli bileşiklere benzemektedirler. Dört izoindolin biriminin kondenzasyonu ile oluşan ftalosiyaninler yapisal olarak tetrabenzotetraazaporfirin olarak da isimlendirilmektedir. Ftalosiyaninler doğal olarak oluşmamakla birlikte molekül şekli olarak hemoglobin, klorofil II ve B12 vitamini gibi doğal porfirin türevleri ile yüksek homoloji gösterirler (Şekil 1) (Chunyu ve ark., 2007).

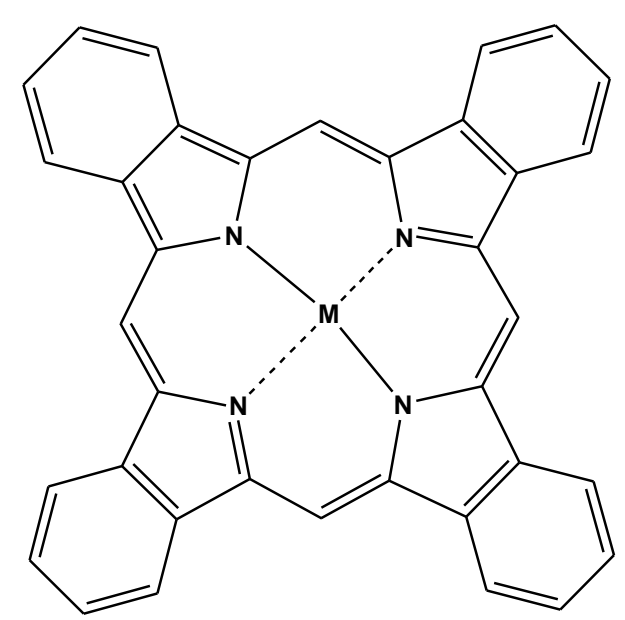

Şekil 1. Metalli ftalosiyaninin molekül yapısı.

Ftalosiyanininlerin fiziksel ve kimyasal özellikleri merkezlerinde metal olup olmamasina göre değişmektedir ve bu nedenle renkleri koyu maviden kirli yeşile ve hatta metalik bronza kadar çeşitlilik göstermektedir. Çoğu ftalosiyaninlerin erime noktaları bulunmamaktadır ve ayrıca suda ve organik çözücülerde çözünürlükleri oldukça düşüktür.
Ftalosiyaninlerin genellikle farklı çözünürlük, renk şiddeti ve kararlılık açısından birbirinden ayrı en az iki kristal modifikasyonu bulunmakla birlikte renk şiddeti (pigment özelliği) en kuvvetli olan türevleri bakır, kobalt ve nikel ftalosiyaninlerdir (Bhoge ve ark., 2014).

Pigment olarak ticari öneme sahip tek ftalosiyanin bakır ftalosiyaninlerdir. Unsubstitüe bakır ftalosiyaninler mavi pigment olarak kullanılırken halojenlenmiş olan bakır ftalosiyaninler yeşil pigment olarak kullanılmaktadırlar. Ftalosiyanin türevli pigmentlerin \%90-95'ini boyada, baskı mürekkeplerinde ve plastikte kullanılan mavi ve yeşil renkler oluşturmaktadır (The British ColourMakers' Association, 1981). Dünya pigment pazarında toplam organik pigmentlerin \%15'inden fazlasını bakır ftalosiyaninler oluşturmaktadır (Aravindakshan, 2005). Ticari olarak üretilen bakır ftalosiyanin türevli pigmentler ve bazı özellikleri ile kullanım alanları aşağıda özetlenmiştir (Çizelge 1). Ftalosiyanin türevli pigmentler dünya genelinde bir çok üretici tarafından üretilmekle birlikte pazara başta Hindistan olmak üzere uzak doğu ülkeleri oldukça hakimdir (Lomax, 2005).

Uluslararası renk indeksi (CI) kodlarına göre dünya genelinde PB15:0 kodlu pigment 74 üretici tarafindan, PB15:1 kodlu pigment 63 üretici tarafından, PB15:2 kodlu pigment 32 üretici tarafından, PB15:3 kodlu pigment 68 üretici tarafindan, PB15:4 kodlu pigment 29 üretici tarafindan, PB15:6 kodlu pigment 6 üretici tarafindan, PB16 kodlu pigment 2 üretici tarafindan, PB17 kodlu pigment 5 üretici tarafından, PB76 kodlu pigment 1 üretici tarafından, PG7 kodlu pigment 86 üretici tarafindan ve PG36 kodlu pigment 20 üretici tarafından üretilmektedir. Öte yandan, PB15:5 kodlu pigmentin şuan üreticisi bulunmamaktadır (Lomax, 2005).

Ftalosiyanin kompleksleri hemen hemen periyodik tablodaki tüm metaller ile sentezlenmektedir. Ftalosiyaninler kompleks bir yapıya sahip gibi görünmekle birlikte uygun başlangıc maddelerinin varlığında tek basamaklı reaksiyonla elde edilmektedirler. Ftalosiyanin sentezi reaksiyonu oldukça ekzotermik bir reaksiyondur örneğin ftalonitrilden sentezlenen bakır ftalosiyaninin reaksiyon entalpisi -829.9 kJ/mol'dür. Ftalosiyaninler genellikle ftalik asit türevlerinin (Şekil 2. a-g) ve uygun metal tuzlarının varlığında sentezlenmektedirler (Wanser, 1985).

$\mathrm{Bu}$ çalışmada, ülkemizde üretilmeyen ancak ithal edilip yaygın bir şekilde kullanılan ftalosiyanin türevli, PB15:1 kodlu (bu kapsamda sentezlenen pigmente HNS 15:1 kodu verilmiştir) pigmentin sentezi, karakterizasyonu ve endüstriyel uygulama örnekleri yapılmıştır. 
Çizelge 1.Pigment olarak kullanılan $\mathrm{Cu}$ ftalosiyanin türevleri.

\begin{tabular}{|c|c|c|c|c|}
\hline CI Adl & CI No & Renk & Tanımı & Başlıca Kullanım Yerleri \\
\hline PB15:0 & 74160 & Parlak mavi & $\begin{array}{l}\text { Düşük stabilite } \quad \mathrm{Cu} \\
\text { ftalosiyanin }\end{array}$ & $\begin{array}{l}\text { Boya, baskı mürekkebi, } \\
\text { kâğıt }\end{array}$ \\
\hline PB15:1 & $74160: 1$ & Parlak mavi & Stabil Cu ftalosiyanin & $\begin{array}{l}\text { Boya, baskı mürekkebi, } \\
\text { plastikler, kaplama }\end{array}$ \\
\hline PB15:2 & $74160: 2$ & Parlak mavi & Stabil $\alpha-\mathrm{Cu}$ ftalosiyanin & $\begin{array}{l}\text { Boya, baskı mürekkebi, } \\
\text { plastikler, } \\
\text { tekstil }\end{array}$ \\
\hline PB15:3 & $74160: 3$ & $\begin{array}{ll}\text { Parlak } & \text { turkuaz } \\
\text { mavi } & \\
\end{array}$ & $\beta-\mathrm{Cu}$ ftalosiyanin & $\begin{array}{l}\text { Boya, baskı mürekkebi, } \\
\text { plastikler, tekstil }\end{array}$ \\
\hline PB15:4 & $74160: 4$ & Parlak mavi & Stabil $\beta$-Cu ftalosiyanin & Boya, baskı mürekkebi \\
\hline PB15:6 & $74160: 6$ & $\begin{array}{l}\text { Parlak kırmızımsı } \\
\text { mavi }\end{array}$ & $\varepsilon^{-\mathrm{Cu} \text { ftalosiyanin }}$ & $\begin{array}{l}\text { Baskı mürekkebi, } \\
\text { plastikler }\end{array}$ \\
\hline PB16 & 74100 & yeşilimsi & Metalsiz $\alpha$-ftalosiyanin & $\begin{array}{l}\text { Otomotiv boyaları, } \\
\text { ahşap, yazı kalemleri }\end{array}$ \\
\hline PB17 & 74180 & Yeşilimsi mavi & $\mathrm{Cu}$ ftalosiyaninBa tuzu & Baskı mürekkepleri \\
\hline PB76 & 742520 & Turkuaz mavi & $\begin{array}{l}\text { Kısmi klorlanmış } \mathrm{Cu} \\
\text { ftalosiyanin }\end{array}$ & Otomotiv boyaları \\
\hline PG7 & 74260 & yeşilimsi & $\begin{array}{l}\text { Klor ile doyurulmuş } \mathrm{Cu} \\
\text { ftalosiyanin }\end{array}$ & $\begin{array}{l}\text { Boya, baskı mürekkebi, } \\
\text { plastikler }\end{array}$ \\
\hline PG36 & 74265 & Sarımsı yeşil & $\begin{array}{l}\text { Kloro, bromo } \\
\text { ftalosiyanin }\end{array}$ & $\begin{array}{l}\text { Boya, baskı mürekkebi, } \\
\text { plastikler }\end{array}$ \\
\hline
\end{tabular}

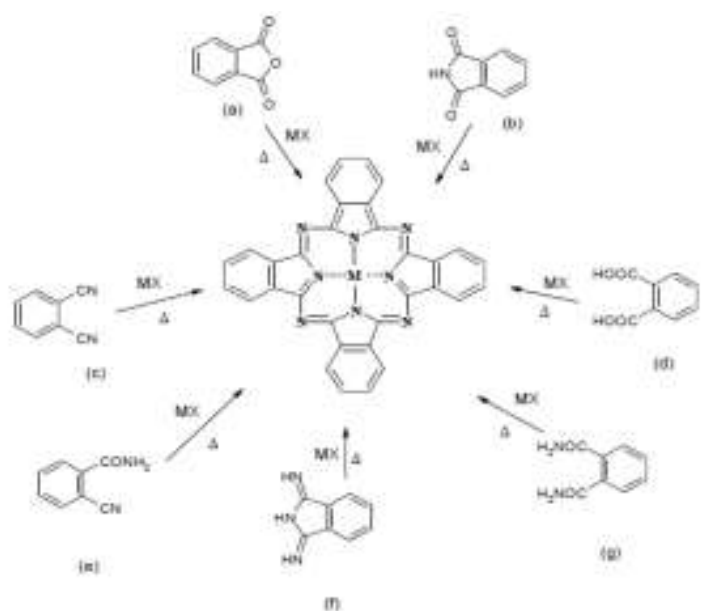

Şekil 2. Ftalosiyaninler için genel sentez şeması.

Pigmentin sentezinde uygun başlangıç maddeleri yağ ısıtmalı bir reaktörde karıştırılmış ve ham ürün elde edilmiştir. Reaksiyondan elde edilen ham ürün yıkanmış, filtre edilmiş ve kurutulmuştur. Elde edien pigment UV-vis., FTIR, MS gibi spektroskopik teknikler ve elementel analiz ile karakterize edilmiştir. Pigmentin endüstriyel uygunluk denemeleri masterbatch, suni deri ve pigment pasta sektörlerinde yapılmıştır.

\section{MATERYAL ve METOD}

\section{Kullanilan Materyaller}

$\mathrm{Bu}$ çalışmada kullanılan ftalikanhidrit (PA) PETKİM'den, üre, bakır tuzları, amonyumheptamolibdat, sodyum hidroksit $(\mathrm{NaOH})$, hidroklorik asit, sülfürik asit ve dimetilsülfoksit (DMSO) Golgi Medikal'den, gliserin TAT Kimya'dan tedarik edilmiştir. Karşılaştırma için kullanılan ticari pigment (T_15:1) BestColor firmasından satın alınmıştır. Ayrıca makine-teçhizat kurulumları, TEKNOMAK firmasından hizmet alımı yolu ile, yapılmıştır.

\section{Kullanılan Cihazlar}

FTIR analizleri Perkin-Elmer Spectrum One FTIR spektofotometresi ile, elementel analiz Thermo Flash EA 2000 CHNS cihazı ile, kütle analizi ise Bruker Autoflexmass spectrometer cihazı ile yapılmıştır. Erime noktası tayini de Stuart smp30 cihazı ile yapılmıştır.

\section{Endüstriyel Denemeler}

Gaziantep Organize Sanayi Bölgesinde faaliyet gösteren BestColor Masterbatch firmasında polietilen plaka, masterbatch, iplik ve ponpon numuneleri çektirilmiştir. Polietilen plakalar \%40 pigment ( $\mathrm{T}_{-} 15: 1$ veya $H N S$ 15:1), \% 60 polietilen (PE) ve \% 10 wax'tan oluşmaktadır. Hazırlanan bu karışım firma laboratuvarında bulunan kalıba dökülmüş ve $180^{\circ} \mathrm{C}$ 'te ısıya maruz birakılarak mavi PE plakalar hazırlanmıştır. Hazırlanan masterbatchler de ise yine plaka çekiminde kullanılan kimyasal ve oranlar alınmıştır. Hazırlanan bu karışım laboratuvar tipi extrüderden $180{ }^{\circ} C^{\prime}$ te geçirilmiş ve granüller halinde kesimi yapılmıştır. Elde edilen polimer taşıyıcılı bu konsantre boya (masterbatch) ile \% 3'lük iplik ve 
pompon hazırlanmıştır.

Diğer taraftan PERSU Suni deri firmasında suni deri numuneleri yaptırılmıştır. Suni deri çekiminde öncelikle \% 30 pigment ( $\mathrm{T} \_15: 1$ veya $\mathrm{HNS}$ 15:1) ve \% 70 dioktilteraftalat (DOTP) kullanılarak suni deriye rengini veren pasta hazırlanmıştır. Hazırlanan bu pastadan \% 5 ve suni derinin hammaddesi olan polivinilklorür (PVC) polimerinden \% 95'lik oranlarda alınarak karışım oluşturulmuştur. Bu karışım üretim hattından $250{ }^{\circ} \mathrm{C}$ 'te geçirilerek suni deri filmleri oluşturulmuştur.

\section{HNS 15:1 Pigmentinin Sentezi}

Ftalikanhidrit, üre, bakır tuzu belirli oranlarda (molce 4:6:1) karıştırılarak önceden içerisine gliserin (30 lt) eklenmiş pilot reaktöre aktarılmıştır. Karışım içerisindeki maddeler tamamen çözündükten sonra üzerine katalitik miktarda (toplam karışımın molce \% 0,1'i kadar) amonyum heptamolibdat eklenmiştir. Reaksiyon iyi bir karıştırma ve ortalama $180{ }^{\circ} \mathrm{C}$ civarında 6 saat takip edilmiştir. Oda sıcaklığına kadar soğutulan ham ürün önce süzülmüş ve bol su ile yıkanmış ve daha sonra da kurutulmuştur. Ham ürün derişik sülfürik asitte çözülerek uygun bir çözücüde çöktürülmüş, filtrasyon, yıkama ve kurutma işleminden sonra karakterize edilmiştir. Verim \%95, E.n > 300ロC. UV-vis., $\lambda \max$ (nm) (DMSO'da): 670.FTIR ( $\left.\mathrm{cm}^{-1}\right)$ : 3010-3047 (Ar-H). MS (MALDI TOF): $\mathrm{m} / \mathrm{z}: 576[\mathrm{M}]^{+}$. Elementel Analiz, $\mathrm{C}_{32} \mathrm{H}_{16} \mathrm{CuN}_{8}$ için hesaplanan: \%C, $66.72 ; \% \mathrm{H}, 2.80 ; \% \mathrm{~N}, 19.45$. Bulunan $\% \mathrm{C}, 66.58 ; \% \mathrm{H}, 3.02 ; \% \mathrm{~N}, 18.95$.

\section{BULGULAR ve TARTIŞMA}

\section{Sentez ve Karakterizasyon}

Ticari 15:1 ( $\mathrm{T} \_$15:1) pigmentine alternatif olabilecek yerli üretim prototip mavi pigmentin (HNS 15:1) başlangıcı olan CuPc'nin sentez şeması aşağıda verilmiştir (Şekil 3). Ftalikanhidrit bileşiğinin, azot kaynağ 1 olarak üre, metal kaynağı olarak $\mathrm{CuCl}_{2}$ ve katalizör olarak ise amonyumheptamolibdat varlığında $200{ }^{\circ} \mathrm{C}$ 'de 4 saat süren halka katılması reaksiyonundan HNS 15:1 pigmentinin başlangıç maddesi elde edilmiştir. Sentez sırasında, en yüksek verim ve en az safsızlık eldesi için, başlangıç hammaddelerinin oranları ve reaksiyon şartları optimize edilmiştir. Pigmentasyon işlemi için reaksiyon sonrası elde edilen ham ürünün önce saf su ile daha sonra sirası ile seyreltik $\mathrm{NaOH}$ ve $\mathrm{HCl}$ çözeltileri ile yıkanarak kurutulmuştur. Kuruyan ürün sülfürik asitte çözülmüş daha sonra suda çöktürülerek tekrar süzülmüş, kurutulmuş ve bu şekilde HNS 15:1 pigmenti elde edilmiştir. Sentez ve pigmentasyon şartlarının optimizasyonunda, daha önce yapılan çalışmalar (Sakamoto ve Ohno, 1997, Reddy ve Keshavayya, 2002) da referans alınmış ancak HNS 15:1 pigmentinin hazırlanmasındaki tüm adımlar yeniden belirlenmiştir. Ftalosiyaninlerin sentezinde yüksek verim için genellikle inert ortam tercih edilmektedir (Durmuş ve Nyokong, 2007). Bu çalışmada inert gaz kullanılmamasına rağmen ftalikanhidrit bileşiğine bağlı fonksiyonel grup olmamasından dolayı HNS 15:1 pigmentinin başlangıç bileşiği $\mathrm{CuPc} \% 95$ verimle elde edilmiştir.

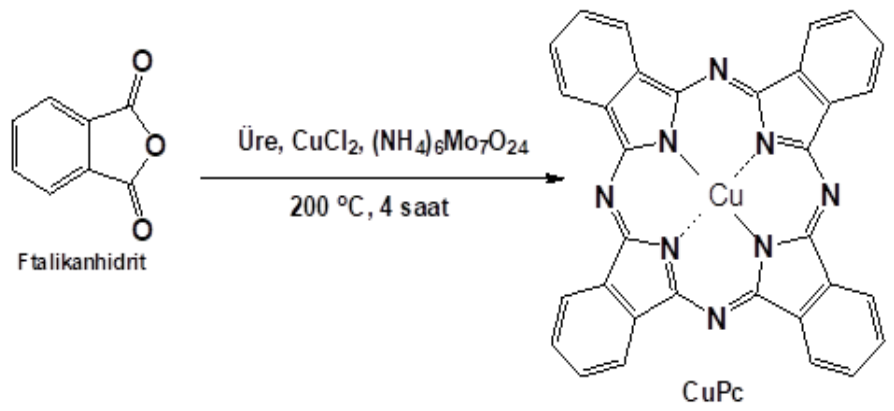

Şekil 3. HNS 15:1 Pigmentinin başlangıcı olan CuPc molekülünün genel sentez şeması.

Pigmentasyon sonucu elde edilen HNS 15:1 pigmenti farklı spektroskopik yöntemler ve elementel analiz kullanılarak literatüre göre (Borker ve Salker, 2006, Ziaefar ve ark., 2011) karakterize edilmiştir. Karakterizasyonun her adımı ticari pigment (T_15:1) için de tekrarlanmış sonuçlar HNS 15:1 ile karşılaştırılmıştır.

Ftalosiyaninler, UV spektrumlarında Q (660-700 nm aralığında) ve B (300-360 nm aralığında) bantları ile karakterize edilmektedir. $\mathrm{Q}$ bandı metalli ftalosiyaninlerde tek bir pik olarak gözükmesine rağmen metalsiz ftalosiyaninlerde ikiye yarılmaktadır (Mack ve Kobayashi, 2011, Özdemir ve ark., 2016). Pigmentlere (T_15:1 ve HNS 15:1) ait, DMSO çözücüsü içerisinde ve $2, \overline{5}$ × $10^{-5} \mathrm{M}$ konsantrasyonda alınan, UV spektrumları incelendiğinde karakteristik Q bantlarının $670 \mathrm{~nm}$ 'de, B bantlarının ise $350 \mathrm{~nm}$ 'de oldukları tespit edilmiştir (Şekil 4).

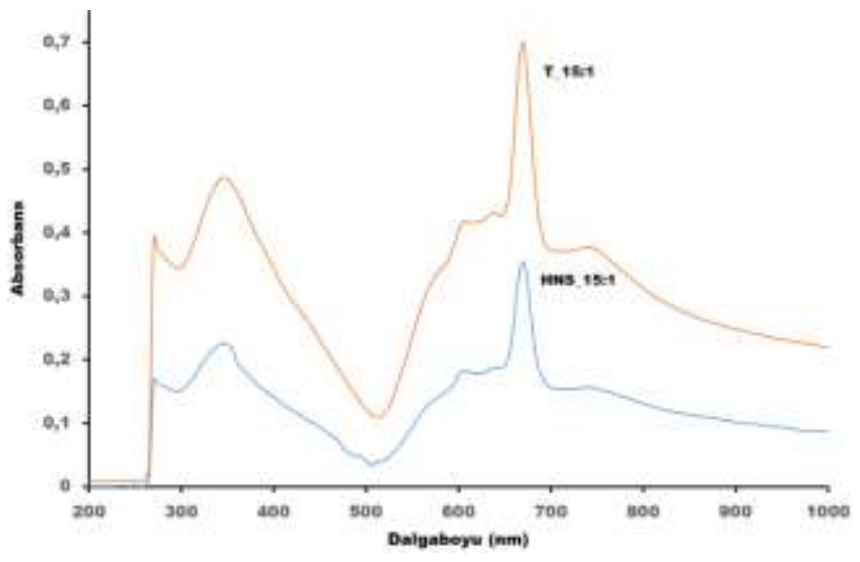

Şekil 4. T_15:1 ve HNS 15:1 pigmentlerinin 2,5 x 10-5 M konsantrasyondaki UV-vis. spektrumları. (Çözeltiler DMSO çözücüsü kullanılarak hazırlanmış ve spektrumda dalga boyuna karşılık absorbans ölçülmüştür.) 
Spektrumdaki görülen omuz piklerinin ise pigmentlerin çözücü içerisindeki agregasyon davranışlarından kaynaklandığı öngörülmektedir (Ozer ve ark., 2006, Yılmaz ve ark. 2014).

T_15:1 ve HNS 15:1 pigmentleri için FTIR spektrumları da ATR tekniği ile ölçülmüş ve sonuçlar hem kendi için de hem de literatür (Reddy ve Keshavayya, 2002) ile karşılaştırılmıştır. Spektrumda özellikle orta infrared bölgedeki piklerin her iki numune için de hemen hemen aynı yerlerde oldukları görülmüştür. Bileşiklere ait spektrum incelendiğinde fonksiyonel grup bölgesinde aramotik halkaya ait gerilme titreşim piklerinin 3010-3047 $\mathrm{cm}^{-1}$ aralığında olduğu tespit edilmiştir (Şekil 5). HNS 15:1 pigmentinin FTIR spektrumunun fonksiyonel grup bölgesi yapıda yalnızca aromatik hidrojenlerin olduğunu göstermektedir. Bu bölgedeki diğer piklerin ise her iki pigment için de reaksiyona girmemiş başlangıç hammaddelerine ve reaksiyonda oluşan yan ürünlere ait olduğu düşünülmektedir.

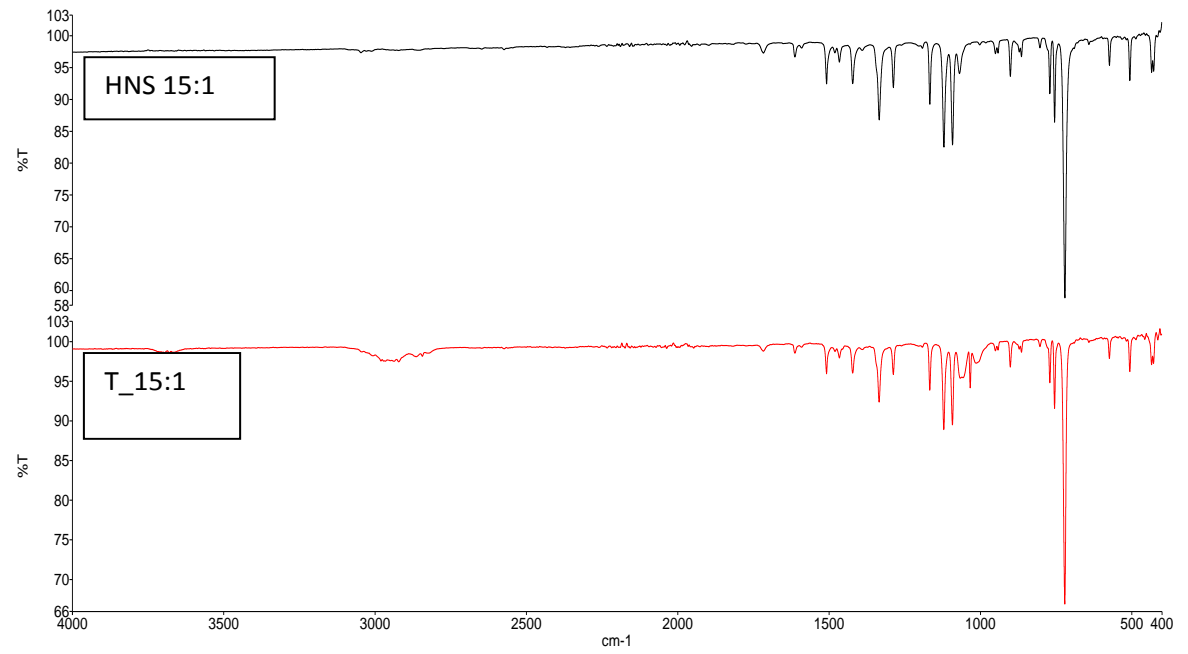

Şekil 5. T_15:1 ve HNS 15:1 pigmentlerinin ATR tekniği ile ölçülen FTIR spektrumları. FTIR spektrumlarında dalga sayısına karşılık \% geçirgenlikler ölçülmüş ve her iki spektrum çakıştırılmıştır.

Bakır metalinin paramanyetik özelliğinden (Yılmaz ve ark., 2015) dolayı pigmentlerin NMR spektrumları alınamamıştır. Bileşiklerin spektroskopik parçalanmaya uğramadan mol kütlelerinin belirlenmesinde MALDI TOF MS spektroskopisi kullanılmaktadır ve bu teknikte moleküllerin kütle / yük $(\mathrm{m} / \mathrm{z})$ oranlarına karşllı pik şiddetleri ölçülmektedir (Rapulenyane ve ark., 2012). Pigmentlerin MALDI TOF kütle spektrumlarına bakıldığında (Şekil 6) her iki numunenin de aynı mol kütlesine sahip olduğu görülmüştür. Yalnızca T_15:1 pigmentinin analiz şartları ve kullanılan matrikse bağlı olarak pik şiddeti HNS 15:1'e kıyasla daha düşük görülmüştür. HNS 15:1 pigmentinin teorik olarak hesaplanan mol kütlesi ile spektrumdan elde edilen değer uyum içerisinde olup bu durum bileşiğin başarılı bir şekilde sentezlendiğini göstermektedir. Ayrıca HNS 15:1 pigmentinin elementel analiz sonuçları da teorik olarak hesaplanan ile uyum içerisindedir. Tüm bu karakterizasyon tekniklerinden alınan sonuçlar literatür (Lomax, 2005) ile kıyaslandığında HNS 15:1 pigmentinin başarılı bir şekilde hazırlandığı ve iyi bir şekilde saflaştırıldı̆̆ı sonucuna varılmıştır.
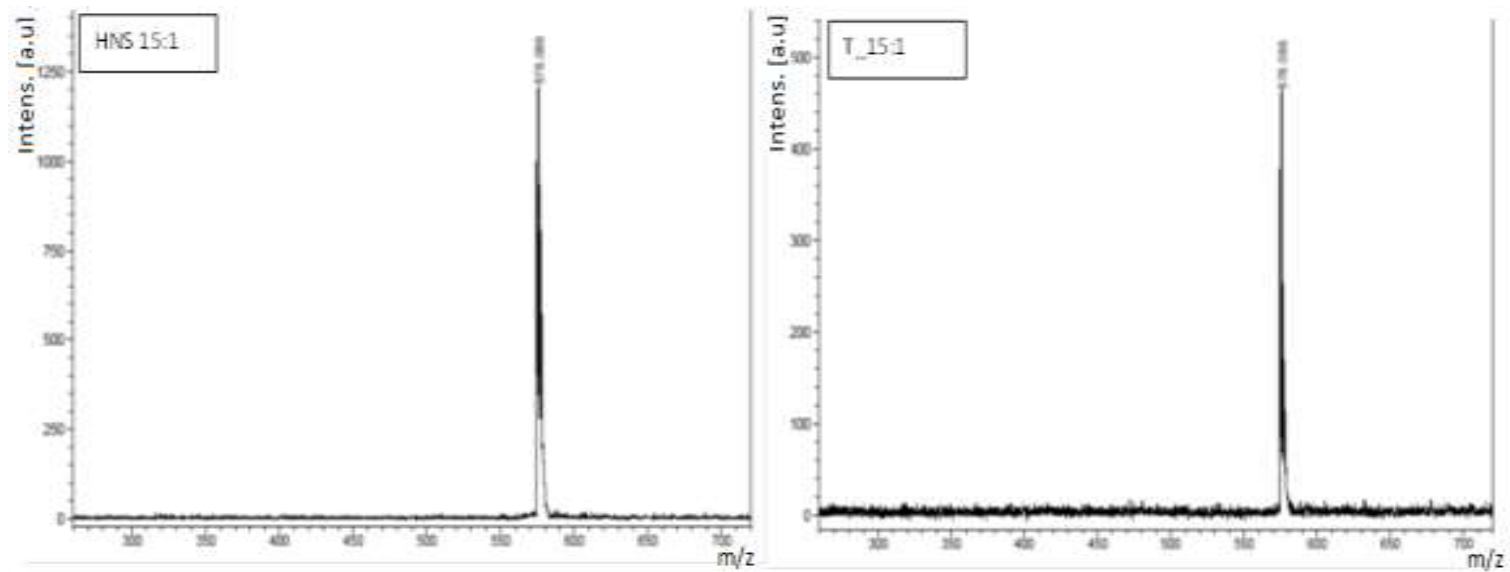

Şekil 6. HNS 15:1 ve T_15:1 pigmentlerinin 2,5-dihidroksibenzoik asit (DBH) matriksinde ölçülen, kütle/yük'e karşılık pik şiddetini içeren MALDI TOF MS spektrumları. 


\section{Endüstriyel Uygunluk Denemeleri}

$\mathrm{Bu}$ çalışma kapsamında hazırlanan mavi pigment yukarıda da bahsedildiği gibi bir çok sektörde kullanılmaktadır (Ziaefar ve ark., 2011). Ticari prototip olarak hazırlanan HNS 15:1 kodlu pigmentin karakterizasyon sonuçları ticari pigmentin sonuçları ile aynı olduğundan HNS 15:1 pigmentinin endüstriyel uygunluğu da denenmiştir. Bu kapsamdaki denemeler yalnızca HNS 15:1 pigmentinin endüstriyel ortamda çalışıp çalışmadığı üzerine olmuştur. Öncelikle Gaziantep Organize Sanayi Bölgesinde faaliyet gösteren BestColor Masterbatch firmasinda polietilen plaka, iplik ve ponpon numuneleri çektirilmiştir (Şekil 7a, b, c). Yine Gaziantep'te faaliyet gösteren PERSU
Suni deri firmasında suni deri numuneleri yaptırılmıştır (Şekil 7d). Denemeler ticari pigment ile aynı ortam ve şartlarda yapılmış olup HNS 15:1 pigmentinin endüstriyel ölçekteki makinalarda zorlanmadan çalıştığı tespit edilmiştir. Firmalarda yaptırılan numuneler ustalar tarafindan yalnızca gözlem yolu ile boyama gücü, örtücülük ve apraj gibi konularda değerlendirilmiş ve prototip olan HNS 15:1 pigmentinin, makinalarda çalışma açısından bir sıkıntısının olmadığı ancak hazırlık aşamasında daha iyi kurutulması gerektiği şeklinde geri bildirimler alınmıştır. $\mathrm{Bu}$ çalışma kapsamında hazırlanan prototip HNS 15:1 pigmentinin diğer endüstriyel uygunluk denemeleri literatürde yapılan çalışmalara (Gregory, 2000) göre devam etmektedir.
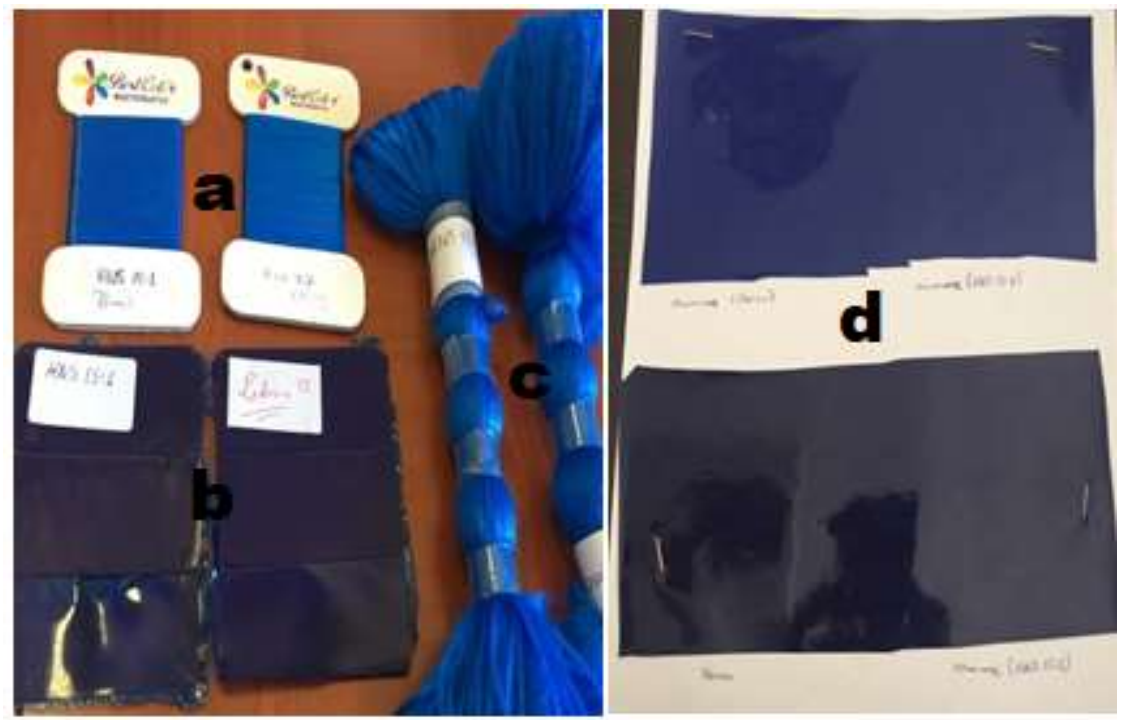

Şekil 7. T_15:1 ve HNS 15:1 pigmentlerinin endüstriyel uygunluk denemeleri. Şekilde, a. polipropilen iplik, b. polietilen plaka, c. polipropilen ponpon ve d. polivinilklorür suni deri numunelerine ait resimlerdir.

\section{SONUÇ ve ÖNERILER}

$\mathrm{Bu}$ çalışmada dünyada 100 binlerce ton üretilen ve ülkemizde de ithal edilip yaygın bir şekilde kullanılan, ftalosiyanin türevli pigmentler tanıtılmış ve yine ftalosiyanin türevli, 15:1 kodlu, pigmentin sentezi karakterizasyonu ve endüstriyel uygunluk denemeleri yapılmıştır. Çalışmada hazırlanan pigmente HNS 15:1 kodu verilmiş olup hazırlanan bu prototip pigment çeşitli spektroskopik teknikler ve elementel analiz kullanılarak karakterize edilmiş, endüstriyel uygunluk denemeleri ise masterbatch ve suni deri sektörlerinde yaptırılmıştır. Bu çalışma kapsamında ticari prototipi üretilen HNS 15:1 kodlu pigmenti oluşturan moleküllerin sentezlerinin, reaksiyon ve pigmentasyon şartlarının, daha yüksek verim ve minimum safsızlık eldesi için geliştirilmesi gerekmektedir. Ayrıca HNS 15:1 pigmentinin endüstriyel uygunluk denemeleri, mürekkep, inşaat ve sanayi tipi boyalar için pasta ve kauçuk sektörlerinde de, pigmentin kullanıldığı tüm alanlarda çalışıp çalışmadığı gibi kavramların belirlenmesi için de yapılmalıdır. Yapılan tüm denemelerden elde edilen ürünlerde pigmentin malzeme üzerindeki ısı, ışık vb. gibi haslık değerleri ile birlikte örtücülük, renk şiddeti ve apraj gibi ölçümleri de bu alanda çalışan laboratuvarlarda test ettirilmelidir. Diğer taraftan ticari öneme sahip ftalosiyanin türevli 15:3 ve Green7 kodlu pigmentlerin Ar-Ge çalışmaları da yapılmalı ve elde edilen prototip ürünlerin endüstriyel açıdan uygunlukları denenmelidir.

\section{TEŞEKKÜR}

Bu çalışma TÜBİTAK TEYDEB (Proje No: 2170243) tarafından desteklenmiş ve Gaziantep Teknopark'ta kurulu HNS Kimya Tekstil Danışmanlık San. ve Tic. Ltd. Şti.'nin katkıları ile tamamlanmıştır.

\section{KAYNAKÇA}

Aravindakshan A 2005. Copperphthalocyanines, Paint and Coatings Industry, 29: 686-692.

Bhoge YE, Deshpande TD, Patil VJ, Badgujar NP, Chaudhari RA, Kulkarni RD 2014. Synthesis of 
Copper Phthalocyanine Blue Pigment: Comparative Evaluations of Fusion, Solvent and Microwave Techniques, International Journal of Applied Engineering Research, 9: 1271-1278.

Borker P, Salker AV 2006. Synthesis, characterization and photocatalytic studies of some metal phthalocyanines", Indian Journal of Chemical Technology, 13: 341-346.

Chunyu M, Guotong D, Yong C, Yu S, Cheng C, Jiang W, Chang Y, Wang X, Cong F, Yu H 2007. Synthesis and electrochemistry of a substituted phthalocyaninatozinc, Dyes Pigments, 72: 267-270.

Durmuş M, Nyokong T 2007. Synthesis, photophysical and photochemical properties of aryloxy tetrasubstituted gallium and indium phthalocyanine Derivatives, Tetrahedron, 63: 1385-1394.

Gregory P 2000. Industrial applications of phthalocyanines, J. Porphyrines and Phthalocyanines, 4:432-437.

Lomax SQ 2005. Phthalocyanine and quinacridone pigments: their history, properties and use, Studies in Conservation, 50: 19-29.

Mack J, Kobayashi N 2011. Low Symmetry Phthalocyanines and Their Analogues, Chem. Rev., 111: 281-321.

Ozer M, Ozkaya AR, Bulut M, Bekaroglu O 2006. Synthesis characterization and some properties of novel bis pentafluorophenyl methoxyl substituted metal free and metallophthalocyanines, Polyhedron, 25: 3593-3602.

Özdemir L, Yılmaz Y, Sönmez M, Akkurt M, Tahir MN 2016. Synthesis and Crystal Structure of a New Phthalonitrile and Its Phthalocyanines Bearing Diamagnetic Metals. Synthesis and Reactivity in Inorganic, Metal-Organic, and Nano-Metal Chemistry, 46: 110-117.

Reddy KRV, Keshavayya J 2002. Synthesis of symmmetrically substituted octabromopht halocyanine pigments and their characterization, Dyes and Pigments, 53: 187-194.
Rapulenyane N, Antunes E, Masilela N, Nyokong T 2012. Synthesis and photophysicochemical properties of novel zinc phthalocyanines mono substituted with carboxyl containing functional groups, Journal of Photochemistry and Photobiology A: Chemistry, 250: 18-24.

Robertson JM 1936. Quantitative structure determination of the metal- free compound, Journal of the Chemical Society, 1: 1195-1209.

Sakamoto K, Ohno E 1997. Synthesisandelectron transfer property of phthalocyanine Derivatives, Progress in Organic Coatings, 31: 139-145.

The British ColourMakers' Association 1981. Phthalocyaninepigments, Polymers Paint ColourJournal, 171: 252-255.

Wanser CC 1985. Physical and chemical considerations on copper phthalocyanine, Journal of Coatings Technology, 57: 57-62.

Yıldız SZ, Kucukislamoğlu M, Tuna M 2009. Synthesis and characterization of novel flavonoid-substituted phthalocyanines using naringenin, Journal of Organometallic Chemistry, 694: 4152-4161.

Yılmaz Y, Erdoğmuş A, Şener MK 2014. Diphenylethoxy-substituted metal-free and metallo phthalocyanines as potential photosensitizer for photodynamic therapy: synthesis and photophysical and photochemical properties, Turk J Chem., 38: 1083-1093.

Yılmaz Y, Zengin H, Sönmez M 2015. Synthesis and Photoluminescence Properties of Saccharide Conjugated Copper Phthalocyanine via Click Reaction, Synthesis and Reactivity in Inorganic, Metal-Organic, and Nano-Metal Chemistry, 45: 337-341.

Ziaefar N, Arjomandirad F, Mehrabad JT, Shaaba B 2011. Analyzing and Synthesis of copper, cobalt, manganese and zinc phthalocyanines and a study on their pigments, Archives of Applied Science Research, 3: 542-547. 